\title{
Genetic Algorithm Approach to Logistics Transportation and Distribution Problems: A Case Study of Parcel Delivery Services
}

\section{Pendekatan Algoritma Genetika Pada Masalah Transportasi dan Distribusi Logistik : Studi Kasus Jasa Pengiriman Parcel}

\author{
Miftahol Arifin ${ }^{*}$ \\ ${ }^{1}$ Jurusan Teknik Logistik, Institut Teknologi Telkom Purwokerto \\ Jl. DI Panjaitan No.128 Purwokerto Selatan., Kabupaten Banyumas, Jawa Tengah, 53147 \\ email : arifin@ittelkom-pwt.ac.id \\ doi: https://doi.org/10.31315/opsi.v14i2.4903
}

Received: 22 $2^{\text {nd }}$ June 2021; Revised: $19^{\text {th }}$ July 2021; Accepted: $26^{\text {th }}$ July 2021;

Available online: $21^{\text {st }}$ December 2021; Published regularly: December 2021

\begin{abstract}
Transportation and distribution in logistics is a key activity that requires companies to carry out proper planning. One form of planning in transportation is planning the route and the number of shipping fleets. This research aims to get the best shipping route from each transportation in the form of the smallest shipping cost, delivery distance, and shortest time. The approach used to achieve the research objectives is the genetic algorithm (GA) method. In the application of GA, the best delivery mileage is $152 \mathrm{~km}$ with a travel time of 1868 minutes or an average travel time per the mode of transportation of 6.2 hours. The best shipping cost is Rp. 603,000. Route search by genetic algorithm method was also able to find $38.5 \%$ percent of the total combinations of GA generation.
\end{abstract}

Keywords: Genetic Algorithm; Transportation; Logistik; Chromosome

\begin{abstract}
ABSTRAK
Transportasi dan distribusi dalam logistik adalah aktivitas kunci yang menuntut perusahaan untuk melakukan perencanaan dengan tepat. Salah satu bentuk perencanaan dalam transportasi tersebut adalah perencanaan rute dan jumlah armada pengiriman. Tujuan penelitian adalah mendapatkan rute pengiriman terbaik dari setiap transportasi berupa biaya pengiriman terkecil, jarak pengiriman dan waktu terpendek. Pendekatan yang digunakan untuk mencapai tujuan penelitian dengan metoda algoritma genetika (GA). Pada penerapan GA memberikan hasil jarak tempuh pengiriman terbaik adalah adalah $152 \mathrm{~km}$ dengan waktu perjalanan adalah 1868 menit atau rata-rata waktu tempuh per moda transportasi 6,2 jam. Biaya pengiriman terbaik sebesar Rp. 603.000. Penelusuran rute dengan metode algoritma genetika juga mampu mengevaluasi 38,5\% persen dari keseluruhan rute kombinasi dari pembangkitan GA.
\end{abstract}

Kata Kunci: Genetic Algorithm; Transportation; Logistik; Chromosome

\section{PENDAHULUAN}

Dalam konteks logistik, persoalan distribusi dan transportasi menjadi hal penting dalam menunjang pengiriman barang sesuai dengan tujuan yang telah di tetapkan. Problematika yang ada pada pengiriman parcel adalah menentukan bahwa pelayanan pengiriman dan distribusi parcel yang dilakukan telah memenuhi kelayakan ekonomis, efisien, dan feasible sehingga keuntungan perusahaan akan maksimal. Itulah sebabnya, perlu menentukan perhitungan rute perjalanan pengiriman parcel yang terbaik agar diperoleh hasil yang terbaik, efisiensi dan membuat pelanggan merasa nyaman dalam melakukan traksaksi pada perusahaan tersebut.

Untuk menjembatani nilai kepentingan kedua pihak yaitu pelanggan dan perusahaan 
dalam pemenuhan nilai transaksinya, maka perlu dilakukan perhitungan pengirima dengan tepat agar parcel yang dipesan tiba tepat waktu ketangan pelanggan sesuai jadwal yang di sepakati di awal pemesanan. Pada perusahaan XYZ yang merupakan sebuah usaha toko swalayan berlokasi di Yogyakarta, didukung oleh divisi penyediaan parcel (PC). Salah satu tugas divisi PC adalah menyediakan parcel sesuai permintaan pelanggan dan mengirimkannya ke pelanggan dengan beragam rute dan tujuannya. Sampai saat ini, proses penentuan rute pengiriman parcel masih dilakukan secara manual sehingga menyebabkan pengiriman parcel menjadi tidak optimal.

Peningkatan penjualan secara masif terjadi saat libur hari besar nasional seperti perayaan iedul fitri dan perayaan natal. Pihak PT XYZ seringkali mengalami kendala dalam pengaturan distribusi parcel nya, yaitu menentukan rute pengantaran parcel ke pelanggan agar semua pesanan bisa diantar sesuai kesepakatan dan tujuan yang diminta. Hal ini perlu dilakukan mengingat banyaknya pesanan parsel masuk dan seringkali minta di antar kepada kolega atau relasi si pemesan yang berada pada lokasi berbeda-beda. Hal inilah yang seringkali menjadi kendala mengingat keterbatasan jumlah tenaga kerja pengantaran dan moda tranportasinya, termasuk didalamnya adalah kendala rentang waktu pengiriman yang terbatas juga. Sehingga pengaturan pengiriman menjadi hal penting dan urgent untuk diselesaikan.

Dengan beragamnya rute dan jarak tempuh yang ada, penentuan rute selama ini dilakukan secara parsial dan tidak terstruktur. Upaya yang dilakukan oleh pihak pengelola dilakukan dengan trial error berdasarkan pengalaman saja, sehingga belum menjadi solusi dari penentuan pola pengiriman parcel ke tujuan. Hal ini menyebabkan biaya yang timbul dan waktu tempuh pengiriman menjadi tidak sesuai dengan perencanaan.

Untuk dapat menyelesaikan persoalan tersebut, perlu pendekatan dan teknik yang tepat, agar jalur pengiriman memberikan kontribusi pada keuntungan perusahaan. Pendekatan GA (Genetic Algorithm) dapat dijadikan solusi untuk membantu penyelesaian pengiriman parcel ke palanggan dengan bantuan aplikasi komputer. (Habibeh Nazif \& Lee, 2012)(de Oliveira da Costa et al., 2018)

\section{METODE}

Untuk menyelesaikan persoalan rute pengiriman parcel ke pelanggan menggunakan GA, terlebih dahulu menentukan nilai awal sebagai nilai inisialisasi yang akan menjadi dasar dari penempatan awal populasi untuk di evaluasi dan akan menjadi nilai solusi pada tahap berikutnya. Nilai awal yang dihasilkan belum tentu menjadi nilai optimal, sehingga perlu dilakukan penentuan nilai optimalnya. Sehingga nilai optimal yang diperoleh dilanjutkan dengan penentuan nilai yang perlu di reproduksi pada nilai individunya.(Kalyanmoy Deb, 2001)

Individu yang terpilih pada proses persilangan (croosover) dan proses mutasi (mutation) akan memberikan generasi baru sebagai keturunan yang akan menggantikan populasi nilai awal. Nilai awal akan menjadi titik pencarian awal pada rentang nilai solusi terbaik yang dihasilkan dari proses acak. Chromosome yang dihasilkan terdiri dari urutan yang bisa bernilai binary $0 ; 1$, atau nilai integer, nilai floating point, atau nilai huruf $p, q, r, s$ atau bentuk matriks. (Deb, 2001)

\subsection{Pengkodean}

Dalam pengkodean, solusi yang dihasilkan merupakan representasi kode yang mewakili feasible solution (Intan, 2010). Panjang bit dari variabel $t$ diasumsikan sebagai $p$, sehingga ukuran chromoson-nya adalah $k$. Bila panjang kode bit untuk varaibel $x$ adalah $m$, maka panjang kromosom (chromosome size) adalah $m$, dimana (Yu \& Gen, 2010)(Intan,2010):

$$
2^{\mathrm{n}-1}<\left(\mathrm{b}_{\mathrm{t}}-\mathrm{a}_{\mathrm{t}}\right) \times 10^{\mathrm{p}} \leq 2^{\mathrm{n}}-1
$$

dimana :

$$
\begin{array}{ll}
n & =\text { chromosome size } \\
b_{t} & =\text { nilai tertinggi variabel } t \\
a_{t} & =\text { nilai terendah variabel } t \\
p & =\text { Nilai dibelakang koma (akurasi) }
\end{array}
$$

\subsection{Evaluasi crossover}

Sebuah kromosom dinyatakan dengan rangkaian string biner merupakan representasi dari sebuah kromosan yang berevolusi berulang kali (iterative) dan berkelanjutan untuk menjadi generation. Generasi yang dihasilkan pada proses crossover akan menghasilkan kromosom pada setiap generasinya. Sehingga perlu dilakukan evaluasi dengan cara menghitung fitness value. Nilai fitness tertinggi yang dihasilkan oleh kromosom dengan nilai fitness 
(fitness value) akan dijadikan parents pada proses reproduction (Maskooki et al., 2021) (Tasan \& Gen, 2012)Proses evaluasi dilakukan dengan menggunakan operator tukar silang dan mutasi untuk mendapatkan kromosom baru sebagai offspring.(H. Nazif \& Lee, 2010)

Generasi baru yang diperoleh akan membentuk offspring sebagai kromosom baru pada proses crossover dan mutation yang dihasilkan oleh parent. GA akan convergen pada nilai chromosome terbaik dan terpilih yang akan menjadi nilai solusi optimal.(Habibeh Nazif \& Lee, 2012)(Prins, 2004)

\subsection{Objek Kajian}

Objek kajian yang akan dibahas merupakan wilayah yang berada di wilayah DIY dan sekitarnya dengan maksimal jarak tempuh dari pusat kota Yogyakarta adalah $100 \mathrm{~km}$ sehingga node yang terhubung dalam bentuk rute.

\subsection{Asumsi}

Pada persoalan penentuan rute perjalan pengiriman parcel, hal mendasar yang harus dibangun adalah asumsi yang akan menjadi dasar dalam perhitungan diantaranya :

1) Antara pihak PT $X Y Z$ dan pemesan telah mempunyai kesepakat harga dan titik lokasi pengiriman secara pasti.

2) Pendistribusian parcel ke tujuan adalah sebesar jumlah seluruh permintaan consumer pada hari yang sama jadwal pengiriman.

3) Moda transportasi yang digunakan maksimal adalah $\mathrm{N}$ kendaraan

\subsection{Identifikasi Moda dan Muatan}

Moda transportasi yang dipilih mengikuti pertimbangan sesuai dengan kondisi pengiriman dan ketersediaan moda. Sehingga muatan diperhitungkan sesuai dimensi dari moda transportasinya. Tabel 1 memberikan gambaran tentang jenis dan jumlah armada yang digunakan beserta kapasitas pengangkutan rata-rata.

Pendistribusian parcel ke konsumen tersebar hampir ke seluruh wilayah DIY dan Sebagian perbatasan dengan Jawa Tengah seperti Ngemplak, Sleman, Wates, Bantul, klaten dan lain sebagainya. Sedangkan untuk wilayah selain wilayah jangkauan pengiriman langsung akan dilakukan dengan jasa ekspedisi
Tabel 1. Data Jenis Kendaraan dan Kapasitas

\begin{tabular}{cclc}
\hline No & Kode & \multicolumn{1}{c}{ Type } & $\begin{array}{c}\text { Kap Maks } \\
\text { (Unit) }\end{array}$ \\
\hline 1 & T1 & Pick Up Box & 76 \\
2 & T2 & MPV Grand Max & 54 \\
3 & T3 & Pick Up Box & 76 \\
4 & T4 & Pick Up Jumbo & 83 \\
5 & T5 & Cold Diesel & 54 \\
\hline
\end{tabular}

Parcel memiliki ukuran yang beragam, tergantung dari kotak wadah yang diminta atau ukuran kardusnya. Pada dasarnya PT XYZ akan menyediakan parcel dengan ukuran berapapun selama masih dapat diangkut dalam armada yang ada.

Bahan kemasan parcel bisa berupa kayu, kardus, anyaman bambu dan lain sebagainya. Tujuan pengemasan agar parcel selalu dalam keadaan baik dan bisa sampai tujuan juga dalam keadaan baik. Pada tabel 2 memberikan gambaran dimensi luas kabin pengiriman parcel.

Tabel 2. Ukuran Dimensi Kabin Armada

\begin{tabular}{ccccc}
\hline \multirow{2}{*}{ Kode } & \multicolumn{3}{c}{ Dimensi Kabin } & Luas Kabin \\
\cline { 2 - 4 } & $p(m)$ & $l(m)$ & $t(m)$ & $(\mathrm{m} 3)$ \\
\hline T1 & 2,95 & 1.5 & 1.45 & 6,416 \\
T2 & 2,4 & 1,4 & 1,1 & 3,696 \\
T3 & 2,95 & 1.5 & 1.45 & 6,416 \\
T4 & 4.05 & 1.68 & 1,72 & 11,145 \\
T5 & 2,4 & 1,4 & 1,1 & 3,696 \\
\hline
\end{tabular}

\subsection{Lokasi Pelanggan (Rute)}

Data jarak diperlukan untuk pengolahan adalah jarak gudang dengan titik pengiriman. Estimasi jarak antara dua titik akan digunakan sebagai alur pengiriman sesuai google map agar sesuai dengan kondisi nyatanya.

Pada proses pengiriman diperlukan data input yaitu permintaan untuk setiap lokasi, jarak antar lokasi distribusi, dll. Sebagai contoh misalkan diketahui data permintaan (matrix MP) yang merupakan jumlah pengiriman pada suatu titik lokasi dan tabel jarak (matrix JR) yang menjelaskan jarak antar lokasi distribusi seperti pada Tabel 3.

\section{MatrixMP=[34684965473]}

Dalam perhitungan, jarak diasumsikan sebagai waktu riil yang digunakan untuk mengirimkan paket dan untuk meningkatkan akurasi. 
Tabel 3. Matrix Jarak antar pelanggan (KM)

\begin{tabular}{rrrrrrrrr}
\hline & 1 & 2 & 3 & 4 & 5 & 6 & 7 & 8 \\
\hline 1 & 0 & 11 & 6 & 5 & 8 & 3 & 5 & 2 \\
2 & 7 & 0 & 5 & 4 & 13 & 4 & 3 & 4 \\
3 & 9 & 4 & 0 & 5 & 3 & 1 & 2 & 2 \\
4 & 11 & 8 & 9 & 0 & 4 & 3 & 2 & 5 \\
5 & 3 & 2 & 3 & 7 & 0 & 6 & 1 & 6 \\
6 & 4 & 3 & 4 & 2 & 1 & 0 & 4 & 3 \\
7 & 1 & 2 & 2 & 3 & 5 & 4 & 0 & 2 \\
8 & 3 & 2 & 5 & 4 & 7 & 2 & 3 & 0 \\
\hline
\end{tabular}

\subsection{Model Jaringan}

Untuk mempermudah dalam penyelesaian dikumpulkan jarak pengantaran dari gudang ke masing-masing lokasi sehingga akan terbentuk sebuah jaringan yang mewakili titik pengantaran seperti pada gambar 1. Dengan ketentuan, bentukan rute yang terjadi, harus sesuai dengan asumsi dan sesuai dengan tujuan yang akan dicapai. Sehingga akan menghasilkan matrix jarak (JR) pengantaran seperti pada Tabel 3.

Dalam penentuan rute distribusi diperoleh sesuai hasil pelacakan google maps. Dimana chromosom adalah pengantaran barang sedangkan gen merupakan node yang akan dikunjungi. Populasi yang terjadi sangat tergantung dari proses penentuan nilai fitnessnya

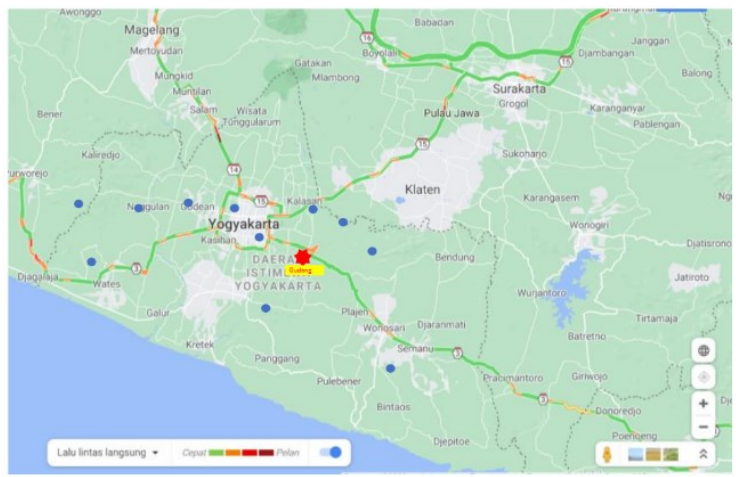

Gambar. 1. Peta lokasi gudang dengan beberapa daerah tujuan pengantaran

\subsection{Perumusan Fungsi Objektif dan Kendala}

Salah point penting dalam penyelesaian dengan algoritma genetika adalah menentukan fungsi objektif dan kendala yang terjadi. Pada kasus penentuan rute pengiriman terdapay tiga hal yang akan menjadi fungi tujuan yaitu 1) Meminimumkan jarak satu rute pada kromosom $\mathrm{k}$, 2) memaksimalkan pengangkutan yang Merupakan fungsi objektif dari total muatan- jarak pada kromosom $k$ dan 3) minimasi biaya pengiriman

Fungsi objektif dan batasan dirumuskan berdasarkan permasalahan dan tujuan yang akan dicapai dari jarak, muatan dan biaya yang ditempuh pada rute $o$ (origin) ke $d$ (destination) pada kromosom $\mathrm{k}$.

\section{Notasi yang digunakan \\ $\mathrm{B}_{\mathrm{od}} \quad=$ Biaya pengiriman parcel dari $o$ ke $d$ \\ $\mathrm{S}_{\mathrm{od}}=$ Harga jual parcel per pelanggan yang dikirim dari $o$ ke $d$ \\ $\mathrm{J}_{\mathrm{od}} \quad=$ Jarak pengiriman dari $o$ ke $d$ \\ $\mathrm{M}=$ Jumlah muatan pada Moda transportasi dari $o$ ke $d$ \\ $\mathrm{P}=$ Parcel yang di pesan \\ $\mathrm{Pc}_{\mathrm{od}}=$ Parcel yang dikirim dari $o$ ke $d$ \\ $\mathrm{Wk}_{\mathrm{d}}=$ Waktu kedatangan moda dilokasi $d$ \\ $\mathrm{Wt}=$ Waktu tempuh moda transportasi \\ $\mathrm{Wb}_{\mathrm{d}}=$ Waktu layanan saat menyerahkan parcel di lokasi $d$ \\ $\mathrm{N}=$ Banyak moda transportasi yang ada \\ $\mathrm{f}_{\mathrm{n}}=\left\{\begin{array}{l}1, \text { Pelanggan menerima parcel } \\ 0, \text { lainnya }\end{array}\right.$ \\ Fungsi Objective:

$$
\begin{array}{ll}
\mathrm{Z}_{1} & \text { Jarak }_{\min }=\sum_{\mathrm{o}} \sum_{\mathrm{d}} \mathrm{J}_{\mathrm{od}} \\
\mathrm{Z}_{2} & \text { Muatan }_{\text {max }}=\sum_{\mathrm{o}} \sum_{\mathrm{d}} \mathrm{M}_{\mathrm{od}} \\
\mathrm{Z}_{1} & \text { Biaya }_{\text {min }}=\sum_{\mathrm{o}} \sum_{\mathrm{d}} \mathrm{S}_{\mathrm{od}}-\mathrm{B}_{\mathrm{od}}
\end{array}
$$

Subject to:

$$
\begin{aligned}
& \mathrm{Pc}_{\mathrm{od}}=\sum_{\mathrm{j}}^{\mathrm{i}} \mathrm{p} \cdot \mathrm{f}_{\mathrm{n}} \\
& \mathrm{Wk}_{\mathrm{d}} \geq \mathrm{Wt}_{\mathrm{d}}+\mathrm{Wb}_{\mathrm{d}} \\
& \sum_{\mathrm{j}}^{\mathrm{i}} \mathrm{y}_{\mathrm{od}}=1 \\
& \sum_{\mathrm{j}}^{\mathrm{i}} \mathrm{y}_{\mathrm{od}} \leq 1 \\
& \mathrm{Wk}_{\mathrm{od}}+\mathrm{Wt}_{\mathrm{od}}+\mathrm{Wb}_{\mathrm{od}} \geq 0
\end{aligned}
$$

\section{HASIL DAN PEMBAHASAN}

Masalah pengiriman merupakan persoalan pengurutan sejumlah rute yang akan dilalui pada node yaitu bagaimana membuat jadwal pengiriman (rute) dari semua pesanan customer dengan meminimasi atau maksimasi fungsi obyektif. Fungsi obyektif merupakan waktu pengiriman total, rata-rata waktu pengiriman, rata-rata waktu keterlambatan pengiriman parcel, atau lainnya.

Tujuan penelitian ini adalah untuk menentukan rute terbaik pada pengiriman parcel 
dari gudang ke pelanggan pada wilayah kajian. Yang dimaksud rute terbaik dalam penelitian ini adalah jalur pengiriman parcel dengan waktu tempuh tercepat, muatan yang bisa di antar maksimal dan tercapainya keuntungan maksimal dari pengiriman parcel.

\subsection{Pengujian Sistem}

Terhadap fungsi objektif seperti pada persamaan (2), (3) dan (4), maka dilakukan penentian nilai rentang nilai objektif yang munggkin pada proses pencariannya. Pada proses GA selanjutnya dilakukan perubahan terhadap parameter nilai crossover dan mutation termasuk menentukan nilai chromosom pada setiap populasi.

Setelah diketahui nilai range yang akan digunakan dalam melakukan proses penyelesaian, maka akan dilakukan proses pengeksekusian kasus kedalam program MOLPuGA (Multi Objective Linier Programming using Genetic Algorithm) yang disusun dengan menggunakan program komputer. Seperti yang di tunjukkan dalam gambar 2.
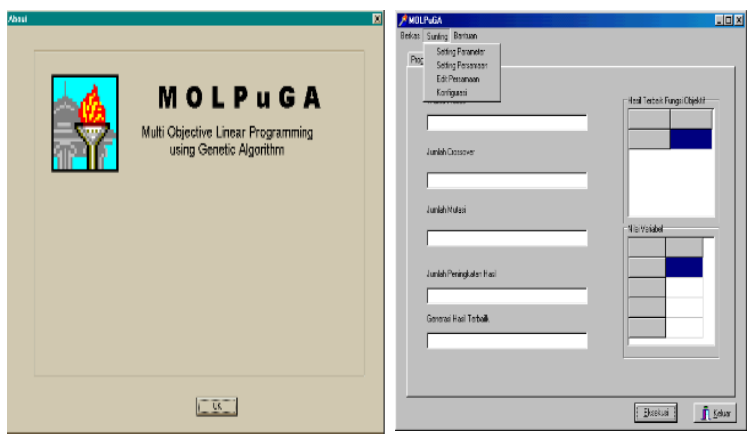

Gambar 2. Tampilan Program dan setting parameter

Sesuai dengan persamaan pada fungsi objektif dan fungsi kendala eksekusi dilakukan untuk menentukan rute tercepat, waktu paling cepat dan biaya pengiriman yang minimal, sesuai keadaan dan kondisi rute yang ada. Koordinat awal pada hari pengujian, dapat ditunjukkan pada gambar 3. Penentuan titik pengantaran dilakukan dengan menentukan titik koordinat, jarak dan lokasi sesuai dengan tampilan dalam google maps sehingga diharapkan memiliki tingkat akurasi data yang baik. Pada kasus minimasi jarak direpresentasikan dengan graph diatas, dimana pada tiap ruas $a_{o d}$ sebagai representasi jarak pada pengiriman dari origin ke destination. ketika node o (origin) terhubung ke $d$ (destination) pada ruas node dengan kondisi jarak minimalis. Jarak minimal merupakan total jarak od yang dilalui.

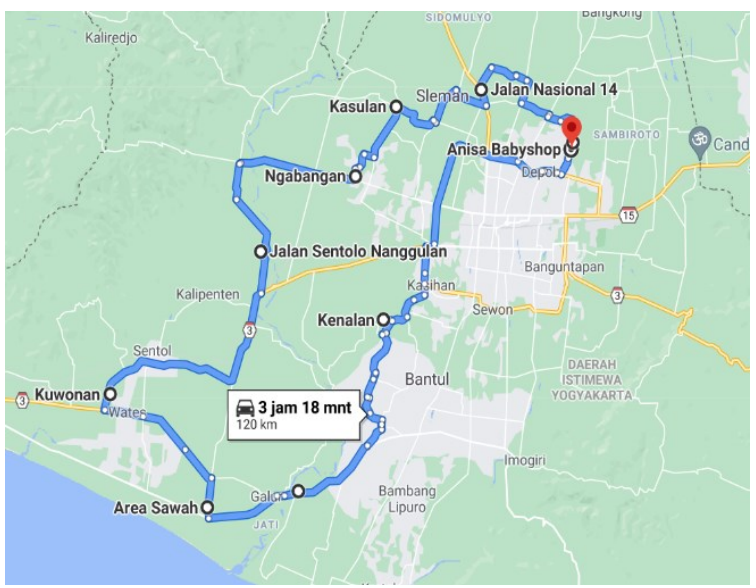

Gambar 3. Representasi Jarak Untuk Satu Moda Transportasi

Fungsi objektif didapat melalui penerjemahan kromosom ke dalam rumusan dan fitness yaitu satu dibagi dengan nilai fungsi objektif ditambah satu.

Rute yang dibentuk oleh bilangan biner 1 pada node mewakili fungsi pada setiap ruas pengiriman. Namun tergantung pada fungsi tujuan yang hendak dicapai, apakah merupakan permasalahan maksimasi atau minimasi baik untuk jarak, biaya dan muatan. Perhitungan fungsi objektif pada kromosom 1 dengan mengacu persamaan (2), (3) dan (4) diperoleh hasil seperti yang disajikan dalam tabel 4 ,

Tabel 4. Nilai Evaluasi Fungsi Objektif

\begin{tabular}{cccccccc}
\hline \multirow{2}{*}{ Chromosom } & \multicolumn{9}{c}{ Node } & \multirow{2}{*}{$\mathrm{F}_{\text {obj }}$} & \multirow{2}{*}{$\mathrm{Fk}$} \\
\cline { 2 - 7 } & $o$ & 1 & 2 & 3 & $d$ & & \\
\hline 1 & 1 & 1 & 1 & 1 & 1 & 13 & 0,11 \\
2 & 1 & 1 & 1 & 0 & 1 & 16 & 0,10 \\
3 & 1 & 1 & 0 & 0 & 0 & 16 & 0,10 \\
4 & 1 & 0 & 0 & 1 & 1 & 11 & 0,13 \\
& & & & & & $\Sigma \mathrm{Fk}$ & 0,44 \\
\hline
\end{tabular}

\subsection{Analisis Perhitungan}

Analisis perhitungan dilakukan terhadap sejumlah faktor yang memiliki keterkaitan ataupun pengaruh pada hasil perhitungan. Sedangkan tingkat efektivitas, dimaksudkan untuk melihat rasio rute yang ditelusuri dibandingkan dengan banyaknya kombinasi yang dihasilkan. Hasil pengamatan grafik perhitungan, diperlihatkan melalui analisis terhadap kecederungan perilaku nilai 
Tabel 5. Rekapitulasi Perhitungan Penugasan Moda Transportasi pengiriman Parcel

\begin{tabular}{|c|c|c|c|c|c|c|c|}
\hline No & Moda Trans & Rute & $\begin{array}{l}\text { Trip } \\
\text { (kali) }\end{array}$ & $\begin{array}{c}\text { Total Jarak } \\
\text { Tempuh }(\mathrm{km})\end{array}$ & $\begin{array}{c}\text { Total waktu } \\
\text { Tempuh (Menit) }\end{array}$ & $\begin{array}{l}\text { Biaya } \\
\text { Kirim }\end{array}$ & $\begin{array}{c}\text { Upah } \\
\text { Pokok/hr }\end{array}$ \\
\hline 1 & $\begin{array}{l}\text { Pick Up } \\
\text { Box }\end{array}$ & $\begin{array}{l}\text { G-28-6-10-17-7-14- } \\
34-3-9-36-39-G\end{array}$ & 4 & 30 & 369 & 45.000 & 75.000 \\
\hline 2 & $\begin{array}{l}\text { MPV Grand } \\
\text { Max }\end{array}$ & $\begin{array}{l}\text { G-18-44-23-11-12- } \\
27-32-13-33-22-G\end{array}$ & 4 & 27 & 393 & 40.500 & 75.000 \\
\hline 3 & $\begin{array}{l}\text { Pick Up } \\
\text { Box }\end{array}$ & $\begin{array}{l}\text { G-31-43-25-46-26- } \\
35-42-29-30-G\end{array}$ & 4 & 31 & 378 & 46.500 & 75.000 \\
\hline 4 & $\begin{array}{l}\text { Pick Up } \\
\text { Jumbo }\end{array}$ & $\begin{array}{l}\text { G-16-2-5-50-19-4- } \\
45-38-15-21-G\end{array}$ & 4 & 32 & 364 & 48.000 & 75.000 \\
\hline \multirow[t]{2}{*}{5} & Cold Diesel & $\begin{array}{l}\text { G-1-41-24-49-40-8- } \\
48-37-47-20-G\end{array}$ & 4 & 32 & 364 & 48.000 & 75.000 \\
\hline & & & Total & 152 & 1.868 & 228.000 & 375.000 \\
\hline
\end{tabular}

maksimum fungsi terhadap nilai rata-ratanya. Batasan disini dimaksudkan untuk menilai perimbangan daerah tujuan dalam pengantaran. Ini disebabkan terdapat beberapa ruas lintasan yang merupakan rute padat.

Melalui perhitungan GA didapatkan nilai obyektif terhadap waktu tempuh pengiriman terbaik adalah adalah $152 \mathrm{~km}$ dengan total waktu tempuh perjalanan pada kelima moda pengiriman adalah 1868 menit atau setara dengan 31,1 jam dengan rata-rata waktu tempuh per moda transportasi 6,2 jam (lihat tabel 5). Untuk menentukan total biaya pengeluaran pengiriman masing-masing moda transportasi ditentukan berdasarkan biaya bensin yang digunakan, yaitu sebesar Rp. 1.500/km. Pada setiap armada maksimal hanya diisi oleh 1 driver dan 1 asisten untuk perhitungan biayanya didasarkan atas Upah tetap harian tanpa upah lembur yaitu Rp. 45.000 untuk Driver dan Rp. 30.000 untuk asisten. Sehingga total biaya pengiriman sebesar Rp. 603.000. Hasil pengujian sistem secara manual juga menghasilkan nilai lebih lama dan biaya lebih mahal, serta memiliki waktu penyelesaian lebih lama.

\subsection{Tingkat Performansi Algoritma Genetika}

Untuk menentukan tingkat efektivitas GA, dilakukan dengan menghitung jumlah kromosom yang terevaluasi dibandingkan dengan total kombinasi yang terbentuk yaitu dengan menghitung $2^{n}-1$ sesuai dengan jumlah kromosom yang terbentuk dari hasil perhitungan program.

Dengan jumlah iterasi per moda sebanyak 2500 kali maka dapat ditentukan tingkat performansi penentuan rute menggunakan GA. Misalnya pada moda 4, maka tingkat performansi-nya sebesar $722 / 1885=38,30 \%$, yang berarti bahwa GA melakukan evaluasi $38,3 \%$ dari seluruh rute yang mungkin terbentuk. Tabel 6, menyajikan perhitungan tingkat performansi pergerakan masing-masing moda angkutan yang dipakai. Moda transportasi dikatakan efektif jika memiliki nilai performansi program tinggi. Artinya bahwa dalam melakukan pelacakan terhadap kombinasi node, telah menghasilkan kombinasi nilai maksimal. Penelusuran rute dengan metode algoritma genetika mampu mengevaluasi 38,3\% persen dari keseluruhan kombinasi rute yang ada. Sehingga dapat dikatakan bahwa GA dalam

Tabel 6. Performansi GA Pada Moda Transportasi

\begin{tabular}{llccccc}
\hline \multirow{2}{*}{ No } & & \multicolumn{5}{c}{ Moda transportasi } \\
\cline { 3 - 7 } & & 1 & 2 & 3 & 4 & 5 \\
\hline 1 & Jumlikator & 696 & 724 & 744 & 722 & 686 \\
2 & Jumlah Chromosome tracing & 1136 & 1355 & 1283 & 1163 & 1151 \\
3 & Jumlah Kombinasi pada node & 1832 & 2079 & 2027 & 1885 & 1837 \\
4 & Performansi Program (\%) & 37,99 & 34,82 & 36,70 & 38,30 & 37,34 \\
\hline
\end{tabular}


melakukan pelacakan rute ini memiliki kapabilitas dan performansi yang baik dalam pengerjaannya.

\section{KESIMPULAN}

Dari pembahasan dapat disimpulkan bahwa GA memiliki kemampuan yang efektif pada pencarian rute terpendek, waktu minimum dengan biaya yang terendah sesuai rute. Waktu tempuh pengiriman terbaik adalah adalah 152 $\mathrm{km}$ dengan waktu tempuh perjalanan adalah 1868 menit atau rata-rata waktu tempuh per moda transportasi 6,2 jam. Biaya pengiriman masing-masing moda transportasi sebesar $\mathrm{Rp}$. 603.000. Penelusuran rute dengan metode algoritma genetika juga mampu mengevaluasi $38,5 \%$ persen dari keseluruhan rute kombinasi pelacakan GA. Sehingga GA dalam pelacakan rute memiliki kemampuan yang baik dalam menghasilkan nilai berdasarkan nilai fitness value nya

Untuk penelitian lebih lanjut dapat memasukkan variabel kepadatan penduduk yang mengakibatkan tingginya aktivitas dan kemacetan yang di timbulkannya.

\section{DAFTAR PUSTAKA}

de Oliveira da Costa, P. R., Mauceri, S., Carroll, P., \& Pallonetto, F. (2018). A Genetic Algorithm for a Green Vehicle Routing Problem. Electronic Notes in Discrete Mathematics, 64. https://doi.org/10.1016/j.endm.2018.01.00 8

Deb, K. (2001). Multi-Objective Optimization using Evolutionary Algorithms Kalyanmoy. In John Wiley \& Sons (Vol. 16, Issue 9).

Intan Berlianty., Arifin M. (2010) Teknik-Teknik Optimasi Heuristik, Graha Ilmu
Kalyanmoy Deb. (2001). Multi-objective optimization using evolutionary programming. In Center for Turbulence Research. Proceedings of the 2000 Summer Program (Vol. 2000).

Maskooki, A., Deb, K., \& Kallio, M. (2021). A customized genetic algorithm for biobjective routing in a dynamic network. European Journal of Operational Research. https://doi.org/10.1016/j.ejor.2021.05.018

Nazif, H., \& Lee, L. S. (2010). Optimized crossover genetic algorithm for vehicle routing problem with time windows. American Journal of Applied Sciences, $7(1)$. https://doi.org/10.3844/ajassp.2010.95.10 1

Nazif, Habibeh, \& Lee, L. S. (2012). Optimised crossover genetic algorithm for capacitated vehicle routing problem. Applied Mathematical Modelling, 36(5). https://doi.org/10.1016/j.apm.2011.08.010

Prins, C. (2004). A simple and effective evolutionary algorithm for the vehicle routing problem. Computers and Operations Research, 31(12), 1985-2002. https://doi.org/10.1016/S03050548(03)00158-8

Tasan, A. S., \& Gen, M. (2012). A genetic algorithm based approach to vehicle routing problem with simultaneous pickup and deliveries. Computers and Industrial Engineering, 62(3). https://doi.org/10.1016/j.cie.2011.11.025

$\mathrm{Yu}, \mathrm{X}$., \& Gen, M. (2010). Introduction to Evolutionary Algorithms. Industrial Engineering and Management Systems, 9(4).

https://doi.org/10.7232/iems.2010.9.4.348 